\title{
Portable X-Ray Fluorescence Spectrometry: Principles and Applications for Analysis of Mineralogical and Environmental Materials
}

\author{
Alexandre H Pinto* \\ Department of Chemistry, Ithaca College, USA
}

*Corresponding author: Alexandre H Pinto, Ithaca College, Department of Chemistry, Center for Natural Sciences, 953 Danby Road, Ithaca, NY, 14850, USA, ORCID ID Number: 0000-0001-9584-8183

Submission: 㥁 December 22, 2017; Published: 眥 February 13, 2018

\begin{abstract}
Portable X-ray Fluorescence (pXRF) is a non-destructive compositional analysis technique, which allows the measurement in field, requiring minimum to no sample preparation. This mini-review presents the physical principles and examples of applications of pXRF for the analysis of mineralogical and environmental samples, such as rocks, soils and sediments. All examples described are from the present decade, in order to show some interesting aspect regarding elemental determination capability, result analysis, or sample preparation. Comparison between the results obtained from $\mathrm{pXRF}$ and other compositional analysis techniques are frequently present in order to show the positive and negative aspects of the pXRF for each type of sample.
\end{abstract}

Keywords: X-ray fluorescence; Portable X-ray fluorescence; Handheld X-ray fluorescence; Minerals; Rock; Soil; Sediments

Abbreviations: EDXRF: Energy Dispersive X-ray Fluorescence; ICP: Inductively Coupled Plasma; ICP-AES: Inductively Coupled Plasma Atomic Emission Spectrometry; ICP-MS: Inductively Coupled Plasma Mass Spectrometry; ICP-OES: Inductively Coupled Plasma Optical Emission Spectrometry; pXRF: portable X-ray Fluorescence; TXRF: total reflectance X-ray Fluorescence; WDXRF: Wavelength Dispersive X-ray Fluorescence; XRF: X-ray Fluorescence

\section{Introduction}

X-ray Fluorescence is a technique used for compositional analysis of materials as solid, powders, liquids, and thin films. Due to its ability to provide reliable qualitative and quantitative information about the composition of materials allied with its non-

destructive character, XRF has been used in many different fields, such as geology [1], petrology [2], mineralogy [3], archaeology [4], agriculture [5], environmental remediation [6], forensics [7], art conservation [8]. a)

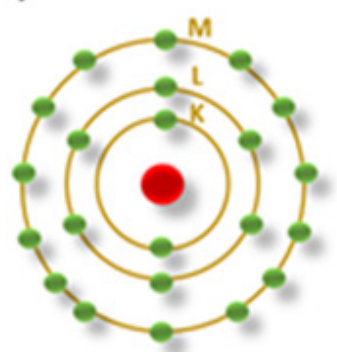

b)

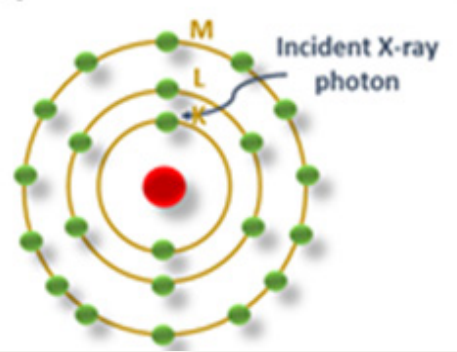

c)

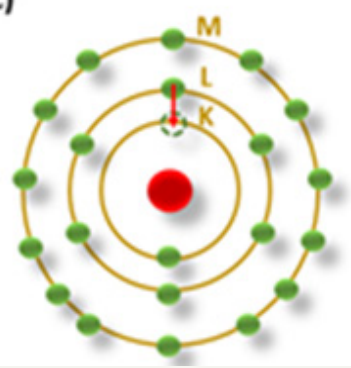

d)

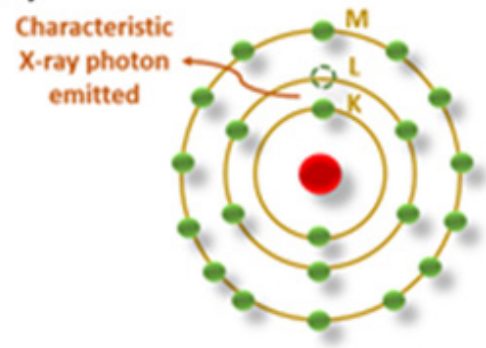

Figure 1: Schematic representation of characteristic X-rays emission,

a) The atomic model is represented as the nucleus (in red) surround by the electrons (in green) distributed in energetic shells (in yellow),

b) An incident X-ray photon transfers energy to an electron located in $\mathrm{K}$ shell (the one closest to the nucleus),

c) The electron is ejected leaving a vacancy in the K shell, d) An electron located in L shell decays to fill the vacancy in the K shell, this decay process is accompanied by emission of a X-ray photon with energy equal to difference between the binding energy of electron in $\mathrm{K}$ shell and the binding energy of electron in $\mathrm{L}$ shell $\left(\mathrm{E}_{\mathrm{X} \text {-ray }}=\mathrm{E}_{\mathrm{K}}-\mathrm{E}_{\mathrm{L}}\right)$. 
The compositional analysis by XRF is based on the physical principle of emission (fluorescence) of characteristic X-rays by a certain chemical element. Explaining this statement more in depth, one can say that when X-rays photons interact with matter many different phenomena can happen as result of this interaction. Among these phenomena, two of them are important to understand the underlying principles of XRF: emission of characteristic X-rays and emission of continuous X-rays. To understand these two phenomena the classical Rutherford-Bohr atomic model, where the atomic nucleus is surrounded by electrons distributed throughout different energetic shells, is a reasonable starting point, as it can be seen from the next section.

\section{Characteristic X-rays}

The production of characteristic X-rays can be understood as being a three-step process, as summarized in Figure 1.

In the first step, an incident X-ray photon penetrates the sample with energy higher than the binding energy of an electron located in the shell closest to the nucleus, this X-ray photon transfer energy to the electron, and as the electron acquires energy higher than its binding energy, it is ejected from the atom. Due to electron ejection, a vacancy is left in the position previously occupied by that electron. Few different events could happen after the ejection of this electron, but the event that is important to understand is the emission of characteristic X-rays. It means that another electron, from a shell farther from the nucleus could decay to the shell closer to the nucleus and fill the vacancy left by the ejected electron. This decay will lead to emission of a characteristic X-ray photon, this emitted X-ray photon is called characteristic because its energy and its frequency are proportional to the difference of the binding energy of the initially ejected electron and the binding energy of the electron that decayed from a shell farther from the nucleus [9]. Besides being proportional to the difference in the binding energy of the two electrons involved in the X-rays emission process, the characteristic X-rays frequency is also proportional to the atomic number of the nucleus. A more quantitative treatment of the relationship for the characteristic X-ray frequency is stated by Moseley's Law, where it is shown that the square root of the frequency of characteristic X-ray (f) is proportional to the atomic number of the nucleus (Z), and two other parameters (k1 and k2) that are dependent on the energetic shells involved in the electron decay that took to the emission of X-rays. Moseley's Law is shown in equation (1) [10].

$$
\sqrt{f}=k_{1}\left(Z-k_{2}\right)
$$

Nowadays the energy of characteristic X-rays emitted by many different elements is well known and readily accessible in tables. A reliable table can be found on X-ray Data Booklet, published by researchers from Lawrence Berkeley National Lab, in California, USA [11].

\section{Continuous X-rays}

When the X-rays photons penetrate the sample, they can be deaccelerated due to interaction with the atomic nucleus; this interaction can be understood as an inelastic process, where part of the energy of the incident X-rays photons is converted to X-rays emitted by the sample.

Unlike characteristic X-rays, continuous X-rays do not have energy directly related to the atomic number of a certain element, so, their energy cannot be used for element identification, however, continuous X-rays are useful for constituting the background observed in X-ray fluorescence spectra.

\section{The X-ray fluorescence spectrum}

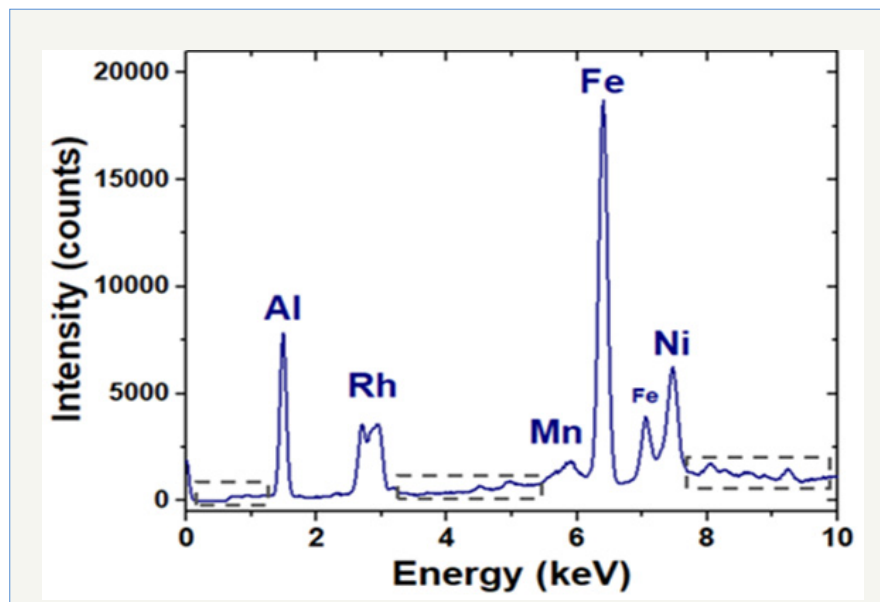

Figure 2: $\mathrm{XRF}$ spectrum of a household Aluminium foil showing characteristic X-ray peaks for $\mathrm{Al}, \mathrm{Fe}, \mathrm{Mn}$, and $\mathrm{Ni}$. The peak from $\mathrm{Rh}$ is interference from the $\mathrm{Rh} \mathrm{X}$-ray source of the equipment. The dashed gray boxes show the continuous X-rays regions.

The X-Ray Fluorescence Spectrum is graph where the Y-axis shows the intensity, and $\mathrm{X}$-axis shows the energy of emitted X-ray photons. It is also possible to observe two different regions in the spectrum, one that is basically formed by sharp peaks, which represent the characteristic X-rays emitted by each detectable element present in the sample, and a second region, which has intensity comparable to the background of the spectrum; this region is related to the emission of continuous X-rays. Figure 2 shows the XRF spectrum of a piece of household aluminium foil obtained using a portable XRF spectrometer. The elements which each characteristic X-ray peak is related to are properly labeled in the spectrum.

\section{Different types of X-Ray fluorescence spectrometers}

The XRF spectrometers can be divided in two main categories: Energy Dispersive XRF (EDXRF) and Wavelength Dispersive XRF (WDXRF). The main difference between these two types of spectrometer lies in the information detected, as the technique names say, in the EDXRF, the energy of different X-rays photons are detected, whereas for WDXRF, it is the wavelength of different $\mathrm{X}$-rays photons that is detected. To accomplish these two different types of detection modes, EDXRF and WDXRF differ from each other regarding the detection system.

For EDXRF the detection device is a lithium-drifted silicon 
crystal ( $\mathrm{Si}(\mathrm{Li})$ detector). This detector performs two roles in the detection system by separating (dispersing) the X-ray photons of different energies, and also detecting their intensity $[9,12]$. Since Si present in the detector is a semiconductor, any X-ray photon having energy higher than the Si band-gap energy ( $\mathrm{Eg} \sim 1.1 \mathrm{eV}$ at room temperature) [13] is able to promote electrons from the valence band to the conduction band of the semiconductor, leaving a hole in the valence band. Since the energy of the X-rays photons emitted during a XRF analysis is the order of magnitude around $103 \mathrm{eV}$, these X-rays photons can easily promote electrons from valence to conduction band of the $\mathrm{Si}$. As the number of electron promoted and holes created is proportional to the energy of X-rays photons, the detector can separate the X-rays photons energies and also relate the X-rays photon energies to their intensities [12]. In this sense, the EDXRF will be graph of intensity (Y-axis) versus energy (X-axis).

The detection system for WDXRF has the energy dispersion and intensity detection roles performed by two separate components. The energy dispersion is carried out by a single crystal, generally LiF (200), this crystal diffracts the characteristic X-ray beams constructively in specific angles, dependent on the interplanar spacing (d-spacing) for that single crystalline dispersive element. After the separation of the X-ray photons of different wavelengths, the intensity is detected by some radiation counter, for instance, a scintillation counter [9]. The WDXRF will be graph of intensity (Y-axis) versus wavelength (X-axis), although the X-axis can be easily converted from wavelength to energy.

The WDXRF has the advantage to present a better energy resolution in relation to EDXRF. A typical energy resolution for WDXRF is around $25 \mathrm{eV}$, whereas for EDXRF it is around $150 \mathrm{eV}$ [14]. In other words, if two elements have characteristic X-rays with energy difference smaller than $150 \mathrm{eV}$, they will not be able to be properly detected by EDXRF, since their peaks will overlap, leading the analysis to a biased result [14]. Another advantage of WDXRF over EDXRF is that WDXRF enables the detection of lighter elements. For instance, ideally, EDXRF would be able to detect elements from sodium to uranium, whereas WDXRF can detect elements from beryllium to uranium $[9,14]$. The advantage of EDXRF is that it enables a faster detection of multiple elements, whereas WDXRF less elements can be detected simultaneously. Additionally, with the technological advances related to electronics miniaturization, portable EDXRF spectrometers are very common devices today, which is not currently possible for WDXRF due to the heavy weight and large size of their diffracting components [9].

Besides EDXRF and WDXRF, there are other modalities of $\mathrm{XRF}$, such as total-reflectance X-ray fluorescence (TXRF), micro $\mathrm{X}$-ray fluorescence (micro-XRF), synchrotron X-ray fluorescence (synchrotron XRF), as the focus of this review is the portable XRF, those other XRF modalities will not be discussed here. For further reading about principles and applications of those other XRF modalities, the review articles by Tsuji et al., West et al., \& Pots et al. [15-18] are recommended.

\section{Portable X-ray fluorescence (pXRF)}

Portable X-ray Fluorescence (pXRF) spectrometers have the advantage to be relatively small and light enabling them to be used for analysis in field with comparable performance in relation to bench top spectrometers. Another advantage is the possibility to be powered by battery eliminating the need for external power outlet source, and generally they have some built-in or easily attachable data storage and processing device, such as a laptop, tablet or handheld computer device [19,20]. Figure 3a shows the picture of the pXRF spectrometer (Bruker Tracer III-V), owned by Department of Chemistry at Ithaca College, which has been used for teaching and research activities [21]. From this picture one can notice that the longest dimension of the equipment is about $28 \mathrm{~cm}$, and the equipment itself weighs around $2 \mathrm{~kg}$. Figure $3 \mathrm{~b}$ shows the sample insertion of one cent dollar coin, remarking the fact that practically no sample preparation is required for a flat and homogenous object, whereas Figure 3c shows the respective XRF spectrum of the coin, showing the characteristic X-rays for copper and zinc, it is important to say that it was necessary only 60 seconds to collect this spectrum.
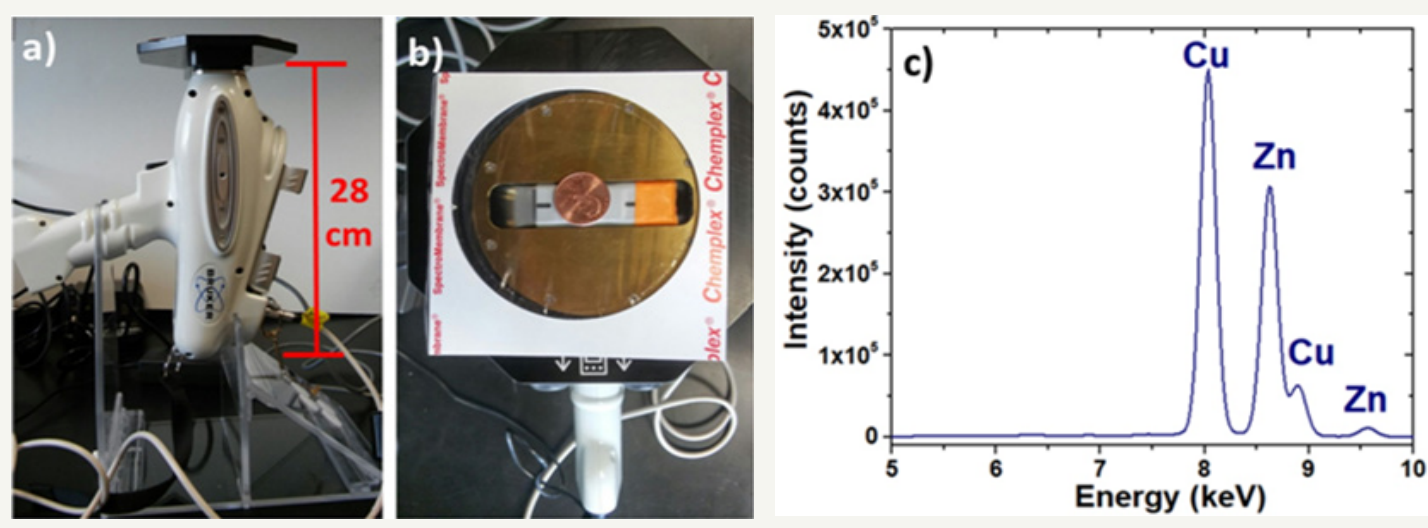

Figure 3: a) Picture of pXRF Bruker Tracer III-V, owned by Chemistry Department at Ithaca College, b) Picture showing with coin how a sample can be mounted for the analysis in the pXRF, besides standing in the holder, as shown in the picture, the spectrometer can also be manually held and pointed to the sample, c) XRF spectrum of the coin showing that it is constituted by $\mathrm{Cu}$ and $\mathrm{Zn}$. 
Despite all the advantages mentioned about pXRF spectrometer, there are also some shortcomings related, for instance, due to the small volume of the sample, for heterogeneous samples it could lead to a source of analytical error [19]. The analysis is also very susceptible to matrix effects, which makes difficult to obtain reliable quantitative results if the standards used do not have an environment as similar as possible to the sample.

\section{pXRF Applied to Mineralogical and Environmental Samples}

Throughout this section, examples of pXRF applications to analysis of rocks, soil and water dredged sediments will be presented underlining the main accomplishments and challenges of pXRF for each type of these materials.

One of the main issues related to the use of pXRF is the influence of matrix effects in the analysis, which makes necessary to develop matrix-specific calibration methods. However, there are few internationally-accepted mud rock or shale reference materials, which do not describe the geochemical diversity of mud rocks. To obtain reliable calibrated results, Rowe and co-workers developed a set of reference materials [22]. This set of reference materials was comprised by a total of 90 samples, where 5 of them were commercial standards and the remaining 85 were collected from five different sources located in the States of Texas and Kentucky in USA. In the development of the calibration method, the concentrations determined by pXRF were compared with the results determined by WDXRF for major elements concentration and with Inductively Coupled Plasma Mass Spectrometry (ICP-MS) or Inductively Coupled Plasma Optical Emission Spectrometry (ICPOES) for trace elements. The developed method provided reliable elemental calibrations for major elements heavier than sodium, and the following trace elements: $\mathrm{Ba}, \mathrm{V}, \mathrm{Cr}, \mathrm{Ni}, \mathrm{Cu}, \mathrm{Zn}, \mathrm{Rb}, \mathrm{Sr}, \mathrm{Y}, \mathrm{Zr}, \mathrm{Nb}, \mathrm{Mo}$, $\mathrm{Th}$, and $\mathrm{U}$. The calibration method was further tested in unknown samples, providing elemental quantification results similar to those provided by WDXRF. These results show the importance of the development of matrix-specific calibration methods, considering a diverse set of calibration standards, and more importantly, that pXRF can be used to produce results as reliable as WDXRF, with all the infield advantages provided by pXRF [22].

Wei Zhang [23] and coworkers used pXRF to obtain the geochemical composition, identify lithologic discriminants, and find alteration/mineralization indicators in rocks located in Mount Pleasant polymetallic deposits in southwestern New Brunswick, Canada. Two main regions inside Mount Pleasant Complex were analyzed: The Fire Tower Zone and the North Zone. The raw pXRF data was calibrated by linear regression equations defined by plotting measured values against certified values of seven certified reference materials. To simplify the collected pXRF dataset, the authors used a chemometrics technique called Principal Component Analysis (PCA). The authors found that an enrichment in Mo and As, and depletion of $\mathrm{Fe}, \mathrm{Mn}, \mathrm{K}$ and $\mathrm{Rb}$ indicating mineralization of $\mathrm{W}$ and Mo in Mount Pleasant area [23].

Quiniou \& Laperche [24] conducted an important study on analysis of $\mathrm{Ni}$ and $\mathrm{Fe}$ ores to determine potential sources of error carried out during infield measurements. They analyzed 98 samples of saprolite and 103 samples of laterite, all extracted from sites located in New Caledonia, a group of islands located in southwestern Pacific. New Caledonia was ranked among the top five Ni ore producers in the world in 2015, according to data from British Geological Survey [25]. The authors found that when the samples are collected, dried, pulverized, pelletized, and then, analyzed in lab setup, in other words, out of field, that there is a good correlation between the data analyzed via PXRF and WDXRF [24].

However, for analysis in field if no sample preparation or correction is carried out, pXRF can lead to biased results. Moisture was considered one of the major sources of error, for instance, intentionally wetted samples when analyzed by pXRF out of field revealed that $\mathrm{Ni}$ and $\mathrm{Fe}$ concentrations are strongly influenced by moisture content [24]. The issue related to moisture content becomes even more serious if the sample is heterogeneous regarding its composition, size and morphology, because the rough external surface and the internal porous structure may hinder the determination of moisture content [24]. This work is important to show that for samples subjected to weathering effects leading to increase moisture content and heterogeneities, that it might be necessary to use sample preparation procedures to minimize the moisture content. The authors underline that although the sample preparation procedure would add more time to the analytical procedure, this additional time would pay off, since results with higher reliability could be obtained.

International shipboard expeditions are other examples of occasions where all the advantages of pXRF are desired. One example is the International Ocean Discovery Program (IODP) Expedition 352 to the Izu-Bonin forearc [26,27]. This expedition had the participation of researchers from many different nationalities and specialties in Physical Sciences that for eight weeks collected volcanic rocks from recovered cores in the Izu-Bonin forearc, which is a tectonic-plate convergent boundary region, located in the Western Pacific Ocean, close to countries like Japan and Taiwan.

In previous expeditions of this program, ICP-OES was commonly used for quantitative elemental analysis; however, the relatively long time for analysis accomplishment, which extended for about one week between sample collection, preparation and end of analysis, was one negative point of this approach. So, pXRF was tried as a possible replacement technique and it presented similar results to ICP-OES. The pXRF generate reproducible results for the elements $\mathrm{K}, \mathrm{Ca}, \mathrm{Ti}, \mathrm{V}, \mathrm{Cr}, \mathrm{Mn}, \mathrm{Fe}, \mathrm{Cu}, \mathrm{Zn}, \mathrm{Rb}, \mathrm{Sr}$, and $\mathrm{Zr}$, either on the powder samples or in rock surfaces. As described by the scientific team that participated on this expedition, pXRF improved the sample selection for shipboard and shore-board analyses, and provided key decision making information useful for drilling operations [26,27].

Soil composition is another area where pXRF can play a decisive role in several fields such as agriculture, for instance, determining which elements are abundant in order to improve fertilizers selection; and environmental remediation, for instance, 
and determining possible soil contamination. Rouillon \& Taylor [28] studied the contaminated soils in Australia using certified reference samples to prepare the calibration curves for pXRF analysis. The unknown soil samples analyzed came from different regions from Australia, exposed in the past to many contaminants, such as $\mathrm{Zn}, \mathrm{Pb}$, and other metals resulting from atmospheric pollution. This research revealed many optimal features of $\mathrm{pXRF}$, for instance, for $\mathrm{Mn}, \mathrm{Pb}, \mathrm{Cu}, \mathrm{Zn}$, and $\mathrm{Cd}$ a great correlation was obtained between the data from pXRF and data from Inductively Coupled Plasma Atomic Emission Spectrometry (ICP-AES). For the certified reference material, parallel measurements using ICP-AES, ICP-MS, and pXRF, revealed that pXRF presented a better performance for quantification of $\mathrm{Ti}$ and $\mathrm{Cr}$ than the other two techniques. In summary, this research showed that pXRF is an ideal substitute for ICP-AES for quantification of $\mathrm{Ti}, \mathrm{Cr}, \mathrm{Mn}, \mathrm{Fe}, \mathrm{Cu}, \mathrm{Zn}, \mathrm{Sr}, \mathrm{Cd}$, and $\mathrm{Pb}$ in metal-contaminated soils [28].

As told previously, analysis of wet samples is a challenging task for pXRF, since the water content can lead to biased quantitative results [24]. However, this difficulty can not hinder the analysis of wet samples, instead, correction methods need to be developed and applied according to the features and possible matrix effects presented by the sample. A remarkable example of suitable analysis of wet materials was described by Lemiere et al. [29] where they analyzed dredged contaminated sediments from waterways. The authors noticed that sediment samples analyzed without any pre-treatment presented water content between 50 to $70 \%$, produced results two to three times lower for $\mathrm{Pb}, \mathrm{Zn}, \mathrm{Cu}$, and $\mathrm{As}$ in comparison to results obtained by ICP-AES for the same samples after dehydration and acid digestion. To solve this problem, they developed a drying procedure where the sample is hand pressed, leading to a $20 \%$ reduction in the water content. After this water content reduction, although the pXRF results do not match completely the ones obtained by ICP-AES, they have a good linear correlation, allowing to estimate the actual concentration from the pXRF concentration in and even rank the $\mathrm{Pb}, \mathrm{Zn}, \mathrm{Cu}$, and $\mathrm{As}$ concentrations in a reliable way [29].

\section{Conclusions}

pXRF is a non-destructive technique, able to analyze elements from $\mathrm{Na}$ to $\mathrm{U}$, to be used in measurements in field, providing fast results with minimum to no sample preparation. Its applications comprise much more than analysis of rocks, soils, and sediments samples, allowing obtaining quantitative and qualitative information from samples in different physical states, such as solids and liquid. Also, pXRF is comparable substitute for other compositional analysis techniques like WDXRF, ICP-MS, ICP-AES, and ICP-OES, and probably has a lower maintenance cost than all ICP based techniques, since unlike ICP based techniques, pXRF does not require the continuous use of an argon flow to produce a plasma, and does not require sample acid digestion procedures in order to be able to perform compositional analysis, which saves time and resources from the equipment operator.

However, there are disadvantages associated with pXRF, for instance, impossibility to analyze elements lighter than $\mathrm{Na}$, and significant influence of matrix effects. So, in order to obtain reliable quantitative results, a pXRF analysis should have standards as similar as the unknown samples to be analyzed to minimize the influence of matrix effects. Certified standards are examples of appropriate reference materials they can be used whenever are possible. Water content is another effect that influences the quantitative determination, which makes more difficult to analyze wet samples. Whenever a wet sample is analyzed it is necessary to establish some type of drying procedure before the analysis or use some type of result analysis correction after the analysis, in both cases it is recommendable that a second compositional analysis technique to be used to certify the results obtained by pXRF. If it is not possible to use a second compositional analysis technique every time, the researcher should consider using it, at least, during the implementation stage of the pXRF analysis procedure.

In summary, pXRF is a compositional analysis technique that geologist, petroleum engineers, mining engineers, mineralogists and other professionals in need of compositional analysis in field should take advantage of, since it is straightforward to use, does not require a laborious sample preparation, and it is cost effective.

\section{Acknowledgments}

The author would like to acknowledge the availability and help of Dr. Chun Li (Ithaca College) with the use of the pXRF spectrometer.

\section{References}

1. Gazley MF, Tutt CM, Fisher LA, Latham AR, Duclaux G, et al. (2014) Objective geological logging using portable XRF geochemical multielement data at plutonic gold mine, marymia inlier, western australia. J Geochemical Explor 143: 74-83.

2. Dai S, Wang X, Seredin VV, Hower JC, Ward CR, et al. (2012) Petrology, mineralogy, and geochemistry of the Ge-rich coal from the wulantuga Geore deposit, inner mongolia, china: new data and genetic implications. Int J Coal Geol 90-91: 72-99.

3. Steiner AE, Conrey RM, Wolff JA (2017) PXRF calibrations for volcanic rocks and the application of in-field analysis to the geosciences. Chem Geol 453: 35-54.

4. Shugar AN (2013) Portable x-ray fluorescence and archaeology: limitations of the instrument and suggested methods to achieve desired results. ACS Symp Ser 1147: 173-193.

5. Lu L, Tian S, Liao H, Zhang J, Yang X, et al. (2013) Analysis of metal element distributions in rice (oryza sativa l.) seeds and relocation during germination based on x-ray fluorescence imaging of Zn, Fe, K, Ca, and Mn. PLoS One 8(2): e57360.

6. Hitchcock a P, Obst M, Wang J, Lu YS, Tyliszczak T (2012) Advances in the detection of As in environmental samples using low energy x-ray florescence in a scanning transmission $\mathrm{x}$-ray microscope: arsenic immobilization by a Fe(ii)-oxidizing freshwater bacteria. Environ Sci Technol 46(5): 2821-2829.

7. Chu PC, Cai BY, Tsoi YK, Yuen R, Leung KSY, et al. (2013) Forensic analysis of laser printed ink by x-ray fluorescence and laser-excited plume fluorescence. Anal Chem 85(9): 4311-4315.

8. Dik J, Janssens K, Van Der Snickt G, van der Loeff L, Rickers K, et al. (2008) Visualization of a lost painting by vincent van gogh using synchrotron radiation based $x$-ray fluorescence elemental mapping. Anal Chem 80(16): 6436-6442.

9. Wobrauschek P, Streli C, Selin Lindgren E (2010) Energy dispersive, $\mathrm{x}$-ray fluorescence analysis. In Encyclopedia of Analytical Chemistry, Chichester, UK. 
10. Moseley HGJ (1914) LXXX. The high-frequency spectra of the elements. Part II. Philos Mag Ser 27: 703-713.

11. Thompson A, Attwood D, Gullikson E, Howells M, Kim KJ, et al. (2009) Center for x-ray optics and advanced light source - x-ray data booklet; ( $3^{\text {rd }}$ edn), Berkeley, USA.

12. Williams DB, Carter CB (2009) Transmission electron microscopy. ( $2^{\text {nd }}$ edn), Springer: Boston, USA.

13. Ma DDD, Lee CS, Au FCK, Tong SY, Lee ST (2003) Small-diameter silicon nanowire surfaces. Science 299(5614): 1874-1877.

14. Huang TC (1992) XRF x-ray fluorescence. In encyclopedia of materials characterization: surfaces, interfaces, thin films. Evans Jr CA, Brundle CR, Wilson S, (Eds.), Butterworth-Heinemann: Stoneham, USA.

15. Tsuji K, Nakano K, Takahashi Y, Hayashi K, Ro CU (2012) X-ray

16. West M, Ellis AT, Kregsamer P, Potts PJ, Streli C, Vanhoof C, et al. (2007) Atomic spectrometry update. X-ray fluorescence spectrometry. J Anal At Spectrom 22: 1304-1332.

17. West M, Ellis AT, Potts PJ, Streli C, Vanhoof C, et al. (2010) Atomic spectrometry update-x-ray fluorescence spectrometry. J Anal At Spectrom 25: 1503-1545.

18. Potts PJ, Ellis AT, Kregsamer P, Marshall J, Streli C, West M, Wobrauschek P (2003) Atomic spectrometry update. X-ray fluorescence spectrometry. J Anal At Spectrom 18: 1297-1316

19. Gałuszka A, Migaszewski ZM, Namieśnik J (2015) Moving your laboratories to the field-advantages and limitations of the use of field portable instruments in environmental sample analysis. Environ Res 140: 593-603.

20. Shackley MS (2012) Portable x-ray fluorescence spectrometry (pXRF): the good, the bad, and the ugly. Archaeol Southwest Mag 26: 1-8. spectrometry. Anal Chem 84: 636-668.

21. Wells G, Haaf M (2013) Investigating art objects through collaborative student research projects in an undergraduate chemistry and art course. J Chem Educ 90: 1616-1621.

22. Rowe H, Hughes N, Robinson K (2012) The quantification and application of handheld energy-dispersive $\mathrm{x}$-ray fluorescence (ed-XRF) in mudrock chemostratigraphy and geochemistry. Chem Geol 324-325: 122-131.

23. Zhang W, Lentz DR, Charnley BE (2017) Petrogeochemical assessment of rock units and identification of alteration/mineralization indicators using portable $\mathrm{x}$-ray fluorescence measurements: applications to the fire tower zone (W-Mo-Bi); and the north zone (Sn-Zn-In), mount pleasant deposit, new brunswick, canada. J Geochemical Explor 177: 61-72.

24. Quiniou T, Laperche V (2014) An assessment of field-portable x-ray fluorescence analysis for nickel and iron in laterite ore (new caledonia). Geochemistry Explor Environ Anal 14(3): 245-255.

25. Brown TJ, Idoine NE, Raycraft ER, Shaw RA, Deady EA, et al. (2014) World mineral production 2011-2015; British Geological Survey Natural Environment Research Council, 2014.

26. Ryan JG, Shervais JW, Li Y, Reagan MK, Li HY, et al. (2017) Application of a handheld x-ray fluorescence spectrometer for real-time, high-density quantitative analysis of drilled igneous rocks and sediments during iodp expedition 352. Chem Geol 451: 55-66.

27. International ocean discovery program-joides resolution science operator (2017) Izu-Bonin-Mariana Forearc International Ocean Discovery Program Expedition 352.

28. Rouillon M, Taylor MP (2016) Can field portable x-ray fluorescence (pXRF) produce high quality data for application in environmental contamination research? Environ. Pollut 214: 255-264.

29. Lemiere B, Laperche V, Haouche L, Auger P (2014) Portable XRF and wet materials: application to dredged contaminated sediments from waterways. Geochemistry Explor Environ Anal 14(3): 257-264.

International License

For possible submission use the below is the URL

- High-level peer review and editorial services

\section{Your subsequent submission with Crimson Publishers will attain the below benefits}

- Freely accessible online immediately upon publication

- Authors retain the copyright to their work

- Licensing it under a Creative Commons license

- Visibility through different online platforms

- Global attainment for your research

- Article availability in different formats (Pdf, E-pub, Full Text)

- Endless customer service

- Reasonable Membership services

- Reprints availability upon request

- One step article tracking system 